\title{
Power port contrast medium flushing and trapping: impact of temperature, an in vitro experimental study
}

This article was published in the following Dove Press journal:

Medical Devices: Evidence and Research

31 August 2013

Number of times this article has been viewed

\section{Gérard Guiffant' Jean Jacques Durussel' \\ Patrice Flaud' \\ Laurent Royon' \\ Pierre Yves Marcy ${ }^{2}$ \\ Jacques Merckx ${ }^{1,3}$ \\ 'University Paris Diderot, Paris, France; ${ }^{2}$ Radiodiagnosis and Interventional Radiology Department, Caen, France; ${ }^{3}$ University Teaching Hospital Necker-Enfants Malades, Paris, France}

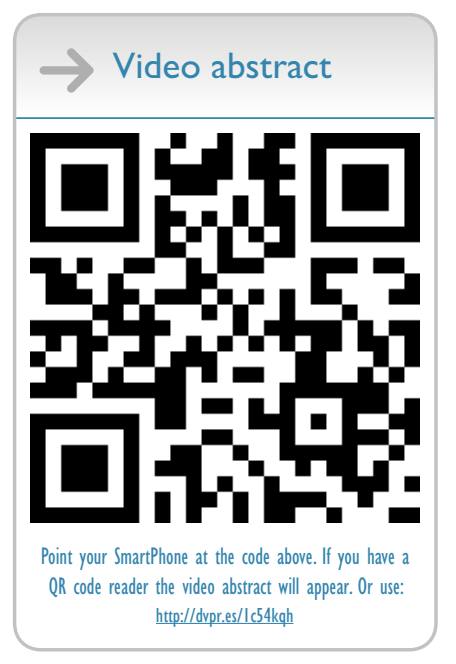

Correspondence: Gérard Guiffant University Paris Diderot, MSC, UMR CNRS 7057, 10 rue Alice, Domon et Léonie Duquet, 75205 Paris, Cedex 13, France Fax +33 0I 572762 II

Email gerard.guiffant@univ-paris-diderot.fr
Purpose: The use of totally implantable venous access devices (TIVADs) certified as "high pressure resistant" or "power port" has begun to spread worldwide as a safe procedure for power contrast injection. Owing to the thermo-rheological properties of the contrast media, the primary aim of this work is to present an in vitro experimental impact study concerning the impact of the temperature level on flushing efficiency after contrast medium injection. Moreover, we report experimental data that confirms the role of needle bevel orientation. The secondary aim is to answer the following questions: Is there significant device contrast medium trapping after contrast medium injection? Is saline flushing efficient? And, finally, is it safe to inject contrast medium through an indwelled port catheter?

Results: The experimental results show that in addition to hydrodynamics, temperature is a key parameter for the efficiency of device flushing after contrast medium injection. It appears that this is the case when the cavity is incompletely rinsed after three calibrated flushing volumes of $10 \mathrm{~mL}$ saline solution, even by using the Huber needle bevel opposite to the port exit. This leads to a potentially important trapped volume of contrast medium in the port, and consequently to the possibility of subsequent salt precipitates and long term trisubstituted benzene nuclei delivery that might impair the solute properties, which may be further injected via the power port later on.

Conclusion: We thus suggest, in TIVADS patients, the use of a temporary supplementary intravenous line rather than the port to perform contrast medium injections in daily radiology routine practice.

Keywords: contrast medium, implantable ports, totally implantable venous access devices (TIVADs), flushing, obstruction, prevention, central lines

\section{Introduction}

For more than two decades, totally implantable venous access devices (TIVADs) have been in use, allowing repeated injection or perfusion for drug administration as well as blood collection. These devices have proven to be safe and effective in overcoming problems of repeated venous access. Furthermore, their characteristics, risks, benefits as well as their usage setting and maintenance are well described and detailed in various protocols and papers in the literature. ${ }^{1-12}$

More recently, the use of TIVADs for power contrast injection has begun to spread as a safe procedure, ${ }^{13-17}$ and is presented as highly desirable from both the patient and the radiologist's point of view. ${ }^{17}$ Besides infectious and thrombotic complications ${ }^{17}$ that are common to all TIVADs, mechanical complications due to the high pressure administration of contrast medium (CM) by automatic injectors tend to become less 
important, thanks to the specification and label "high pressure resistant" of the so-called "power ports". One other complication of injecting CM into the power port lies in the possibility of obstruction of the TIVAD. In spite of the various typical rinsing protocols, the high level of viscosity of the injected CM induces persistence on the endoluminal wall of the TIVADs. The CM settles on the device wall proteins, and absorbs, in turn, part of the chemical or biological infused products. Thus, the definition of dedicated protocols for the indwelled device flushing is clearly of crucial importance.

The primary aim of this paper is to report experimental data regarding the hydrodynamic efficiency on the TIVAD flushing after $\mathrm{CM}$ injection, with special attention paid to the effect of temperature on this process.

We showed in a preceding paper that the dynamic of the device flushing flow plays an essential role ${ }^{18}$ in the effectiveness of rinsing. Moreover, in the particular case of using implantable venous access catheter port devices, we have previously shown ${ }^{19}$ that the orientation of the Huber point needle bevel was a determinant for flushing. The present work is a continuation of this approach.

\section{Materials and methods}

Hydrodynamics and temperature were retained as two key parameters to be assessed to qualify flushing efficiency of TIVADs after CM injection.

The ports being used in the present study included: first, high pressure Polysite ${ }^{\circledR}$ Perouse Medical 4008 (ISP Perouse Medical, Ivry le Temple, France) ports (internal diameter $=13 \mathrm{~mm}$ and internal volume $=0.55 \mathrm{~mL}$ ) connected to an outlet $25 \mathrm{~cm}$ long $8 \mathrm{~F}$ silicone catheter $(1.4 \mathrm{~mm}$ of inner diameter and $2.7 \mathrm{~mm}$ of outer diameter) and; second, Polysite ${ }^{\circledR} 4017$ (ISP Perouse Medical) (internal diameter $=13 \mathrm{~mm}$ and internal volume $=0.55 \mathrm{~mL}$ ) connected to a polyurethane $7 \mathrm{~F}$ catheter $(1.7 \mathrm{~mm}$ of inner diameter and $2.7 \mathrm{~mm}$ of outer diameter) to test and compare between silicone and polyurethane catheters.

Two classes of non-ionic CM were used in the present study. Guerbet (Villepinte France) XENETIX ${ }^{\circledR} 350 \mathrm{mg} / \mathrm{mL}$ has a viscosity of $21 \mathrm{mPa} . \mathrm{s}$ at $20^{\circ} \mathrm{C}$ and of $10 \mathrm{mPa} . \mathrm{s}$ at $37^{\circ} \mathrm{C}$; and Guerbet XENETIX ${ }^{\circledR} 300 \mathrm{mg} / \mathrm{mL}$ has a viscosity of $11 \mathrm{mPa} . \mathrm{s}$ at $20^{\circ} \mathrm{C}$ and of $6 \mathrm{mPa}$.s at $37^{\circ} \mathrm{C}$. These $\mathrm{CM}$ were representative of sixth generation non-ionic monomers. Visipaque $^{\circledR}$ (GE Healthcare, Aulnay sous bois, France) $320 \mathrm{mg} / \mathrm{mL}$ has a viscosity of $26.6 \mathrm{mPa} . \mathrm{s}$ at $20^{\circ} \mathrm{C}$ and of $11.8 \mathrm{mPa} . \mathrm{s}$ at $37^{\circ} \mathrm{C}$, and Visipaque ${ }^{\circledR} 270 \mathrm{mg} / \mathrm{mL}$ has a viscosity of $12.7 \mathrm{mPa} . \mathrm{s}$ at $20^{\circ} \mathrm{C}$ and of $6.3 \mathrm{mPa}$.s at $37^{\circ} \mathrm{C}$. These CM were representative of seventh generation non-ionic dimers. Guerbet XENETIX ${ }^{\circledR} 350 \mathrm{mg} / \mathrm{mL}$ CM associated with Polysite ${ }^{\circledR}$ Perouse Medical 4008 (ISP Perouse Medical) port device was taken as the "standard" reference for the different comparisons with the other "experimental" CMs or materials.

In accordance with the objective of the study, two temperatures of port device flushing (saline $0.9 \%$ sodium chloride) were tested namely at $37^{\circ} \mathrm{C}$ (central body temperature) as well as at $23^{\circ} \mathrm{C}$ (ambient temperature), and two directions of port device flushing including $\alpha=0^{\circ}$ and $\alpha=180^{\circ}$ (Figure 1). The Huber needle (19G) was manually inserted at the center of the port with the bevel opening oriented facing the exit channel $\alpha=0^{\circ}$ or towards the diametrically opposite point of the port, $\alpha=180^{\circ}$. The experimentation was performed in a thermostated enclosure, which maintains power port at $37^{\circ} \mathrm{C}$.

The experimentation was conducted in the following way: the port was first perfused using $100 \mathrm{~mL}$ of $\mathrm{CM}$ $\left(37^{\circ} \mathrm{C}\right)$ at a flow rate of $2 \mathrm{~mL} / \mathrm{second}$. Then, rinsing with saline solution was performed using a series of calibrated saline fractions of $10 \mathrm{~mL}$ at flow rates $0.5 \mathrm{~mL} /$ second $^{17,18}$ that were previously thermalized either at $37^{\circ} \mathrm{C}$ or $23^{\circ} \mathrm{C}$. There was a 1-minute time delay between the two saline solution injections. Each experimentation was conducted using a new port thus without any pre-existing pollution. The content of each syringe was then titrated using an ultraviolet spectrophotometer at $254 \mathrm{~nm}$ (Gilson $112 \mathrm{UV} /$ VIS detector; Gilson, Middleton, WI, USA). The results (ie, $\mathrm{CM}$ remaining in the power port catheter device after saline solution flushing) were calculated on the percentage basis of the total quantity of contrast.

The rheological measurements were performed using a cone plan Haake viscometer allowing the variation of the sample temperature level.

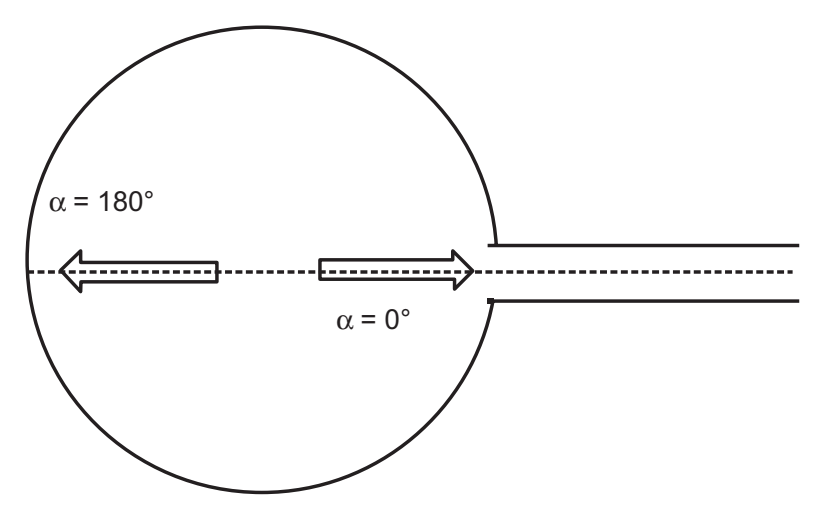

Figure I Bidimensional schematic representation of a port indicating the two directions of the needle bevel orientation. 
The measurements of the thermal conductivity of the $\mathrm{CM}$ at room temperature and at $37^{\circ} \mathrm{C}$ were performed using the TPS 500 hot disk thermal constants analyzer technique, ${ }^{20}$ manufactured by Perkin Elmer Company (Waltham, MA, USA).

\section{Statistical analysis}

The Mann-Whitney $U$ test was used on means $(\mathrm{N}=6)$. Statistical significance thresholds are shown on the figures using the classical correspondence: * for $0.01<P<0.05$; ** for $0.001<P<0.01$; *** for $P<0.001$ The symbol ns indicates not significant.

\section{Experimental results}

The results regarding the standard Guerbet XENETIX ${ }^{\circledR} 350 \mathrm{mg} / \mathrm{mL}$ experimentation are reported in Figure 2A and B. Table 1 shows the results of a series of three successive calibrated syringe fractions of $10 \mathrm{~mL}$ at flow rates $0.5 \mathrm{~mL} / \mathrm{second}$. Each column represents the mean $(\mathrm{N}=6)$ percentage of extracted CM. A logarithmic scale was utilized to clarify result presentation regarding the removed percentages of $\mathrm{CM}$ into the device. Only the first flushing syringe fraction

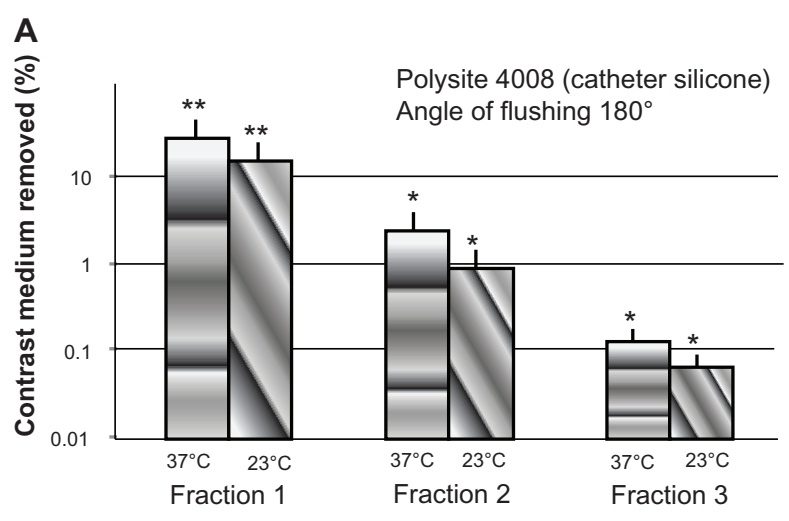

Contrast medium removed (\%)

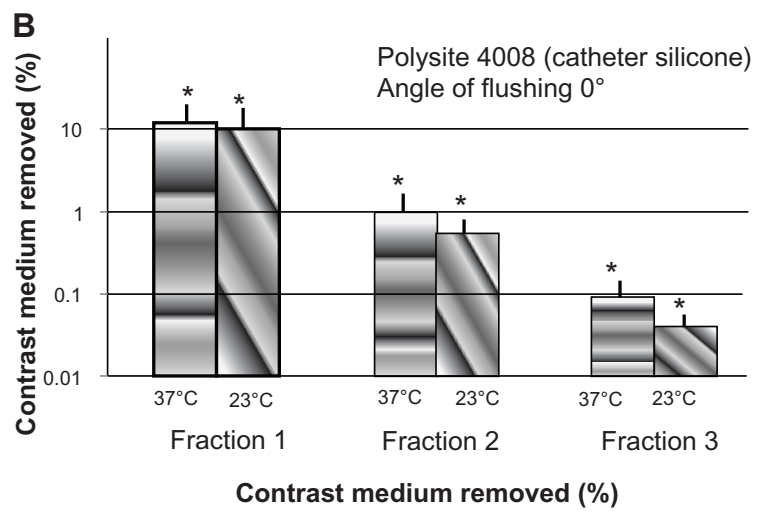

Figure 2 Semi logarithmic representation of the percentage of removed XENETIX ${ }^{\otimes 350}$ after three successive flushing fractions of $10 \mathrm{~mL}$, for two flushing temperatures flushing $\left(37^{\circ} \mathrm{C}\right.$ and $\left.23^{\circ} \mathrm{C}\right)$ and two needle bevel orientations: $\alpha=180^{\circ}(\mathbf{A})$ and $\alpha=0^{\circ}$ (B). Note: Statistical significance is represented by $*$ for $0.01<P<0.05$; $* *$ for 0.00 I $<P<0.01$.
Table I Percentage of removed XENETIX ${ }^{\circledR 350}$ after successive flushing fractions of $10 \mathrm{~mL}$ for the two temperatures $\left(37^{\circ} \mathrm{C}\right.$ and $\left.23^{\circ} \mathrm{C}\right)$ and the two orientations of the needle bevel $\left(\alpha=180^{\circ}\right.$ and $\alpha=0^{\circ}$ )

\begin{tabular}{lcccc}
\hline $\begin{array}{l}\text { Fraction } \\
10 \mathrm{~mL}\end{array}$ & $\begin{array}{l}\mathbf{3 7}^{\circ} \mathbf{C}, \\
\alpha=180^{\circ} \\
\% \text { removed }\end{array}$ & $\begin{array}{l}\mathbf{3 7}^{\circ} \mathbf{C}, \\
\alpha=0^{\circ}\end{array}$ & $\begin{array}{l}\mathbf{2 3}^{\circ} \mathbf{C}, \\
\alpha=180^{\circ}\end{array}$ & $\begin{array}{l}\mathbf{2 3}^{\circ} \mathbf{C}, \\
\alpha=0^{\circ}\end{array}$ \\
\hline 1 & $28 \pm 2$ & $12 \pm 1$ & $15 \pm 1$ & $9.6 \pm 0.5$ \\
2 & $2.3 \pm 0.2$ & $1.1 \pm 0.1$ & $0.9 \pm 0.1$ & $0.57 \pm 0.06$ \\
3 & $0.12 \pm 0.02$ & $0.09 \pm 0.01$ & $0.06 \pm 0.01$ & $0.04 \pm 0.01$ \\
4 to 10 & $0.05 \pm 0.01$ & $0.14 \pm 0.02$ & $0.05 \pm 0.01$ & $0.13 \pm 0.03$ \\
\hline
\end{tabular}

gave significant values. As device flushing was repeated, subsequent fractions gradually led to smaller values of $\mathrm{CM}$ removal until they finally dropped below the detector limit for the last fraction. To facilitate the understanding of the comparisons between experimentation results, the percentage values are reported in Table 1 together with the total amount of $\mathrm{CM}$ removed after ten rinsing fractions.

The results presented in Figure 2A and B were obtained while testing ports associated with silicone catheters. It was then reasonable to investigate the impact of the nature of the port catheter on the efficacy of power port flushing. The results reported in Figure 3 give the percentages of $\mathrm{CM}$ removed after three rinsing fractions of $10 \mathrm{~mL}$ in the most favorable conditions; namely, at $37^{\circ} \mathrm{C}$ temperature and with a needle bevel orientation $\alpha=180^{\circ}$. The material distinction between silicone and polyurethane catheters was found to be non-significant. Although the situation is not clinically relevant, the result obtained without the output catheter has been reported for comparison in Figure 3 as an additional indication. This shows that the CM is mainly trapped into the port itself. As an example, we display a typical image (Figure 4) of the inside (after removing the septum) of a power port chamber, shown after ten rinsing fractions of

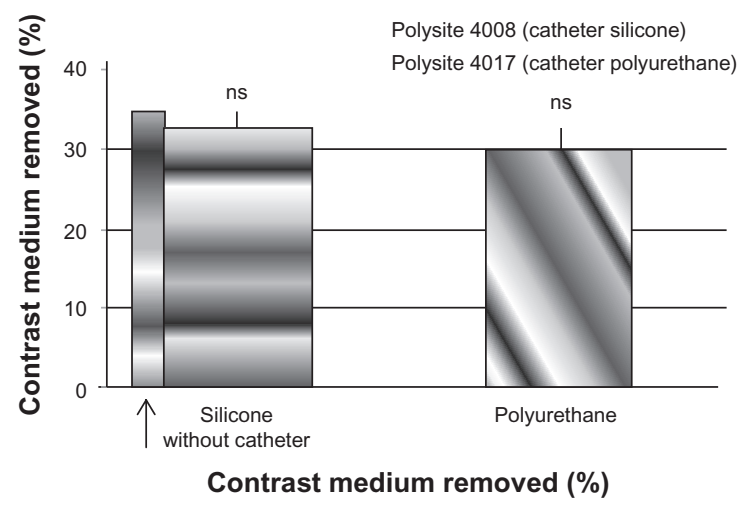

Figure 3 Percentage of removed XENETIX ${ }^{\circledR 350}$ after three flushing fractions of $10 \mathrm{~mL}$ at $37^{\circ} \mathrm{C}$ and $\alpha=180^{\circ}$ for the needle bevel orientation and for two types of catheter: silicone and polyurethane.

Abbreviation: ns, not significant. 


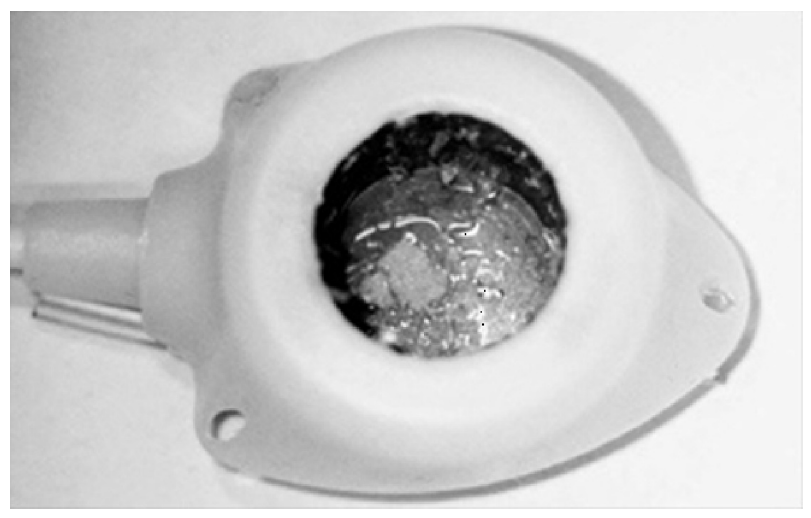

Figure 4 Magnified picture of the interior of a chamber perfused with XENETIX ${ }^{\circledR 350}$ after ten flushing fractions of $10 \mathrm{~mL}$ at $37^{\circ} \mathrm{C}$ and $\alpha=180^{\circ}$.

$10 \mathrm{~mL}$. Indeed, an important quantity of CM is still remaining in the port chamber. The effect of varying the flushing flow level is shown in Figure 5. It was found that the percentage of $\mathrm{CM}$ removed after three rinsing fractions of $10 \mathrm{~mL}$ is not significantly different when comparing the two flows of flushing that were respectively tested at $0.5 \mathrm{~mL} / \mathrm{second}$ and $1 \mathrm{~m} \mathrm{~L} /$ second rates.

Taking XENETIX ${ }^{\circledR} 350$ as the standard reference CM, a comparison was made with different CM. Figure 6 shows the results obtained when comparing the XENETIX ${ }^{\circledR} 350$ to $\mathrm{XENETIX}^{\circledR} 300$; no significant difference was found concerning the rinsing efficiency of the CM after three successive flushing fractions of $10 \mathrm{~mL}$ under the most favorable conditions. The results clearly show that even repeating ten flushing fractions were still ineffective in clearing out the trapping CM.

As mentioned above, XENETIX ${ }^{\circledR} 350$ was taken as representative of the sixth generation of non-ionic monomers of CM commonly used in daily radiology practice. Then, a comparison was carried out by experimenting two repre-

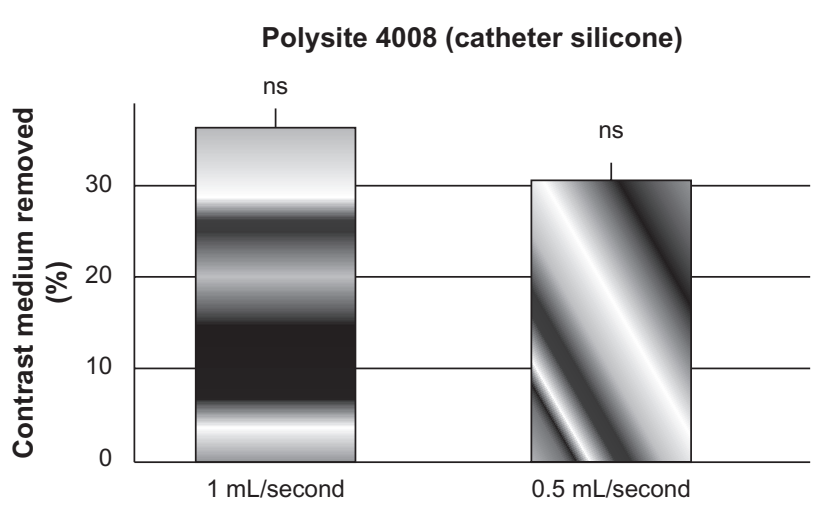

Figure 5 Percentage of removed XENETIX ${ }^{\otimes 3} 50$ after three flushing fractions of $10 \mathrm{~mL}$ at $37^{\circ} \mathrm{C}$ and $\alpha=180^{\circ}$ for two different values of the flushing flow rate. Abbreviation: ns, not significant.

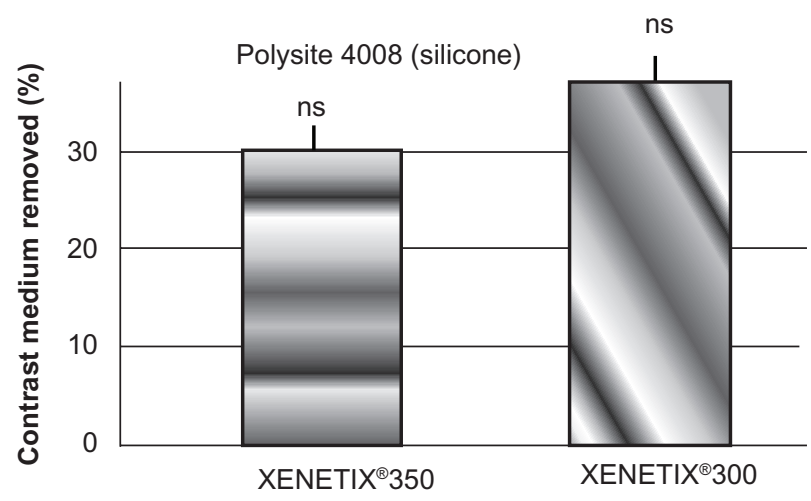

Figure 6 Percentage of removed contrast media after three flushing fractions of $10 \mathrm{~mL}$ at $37^{\circ} \mathrm{C}$ and $\alpha=180^{\circ}$ for XENETIX $^{\circledR 3} 30$ and XENETIX ${ }^{\circledR 3} 300$. Abbreviation: ns, not significant.

sentative $\mathrm{CM}$ of the seventh generation of non-ionic dimers namely Visipaque ${ }^{\circledR} 320$ and Visipaque ${ }^{\circledR} 270$. Figure $7 \mathrm{~A}$ and $\mathrm{B}$ give the efficiency of the flushing after three successive flushing fractions of $10 \mathrm{~mL}$ under the most favorable conditions. Figure 7A shows that no significant difference was found regarding the flushing between XENETIX ${ }^{\circledR} 350$
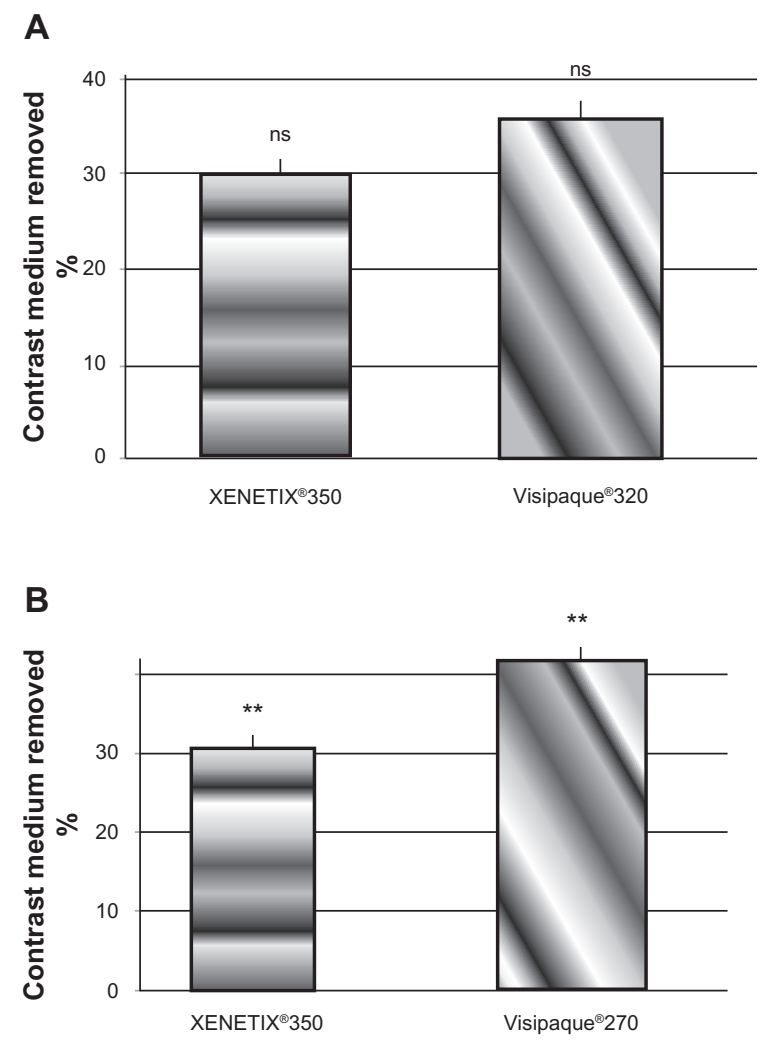

Figure 7 Percentage of removed contrast after three flushing fractions of $10 \mathrm{~mL}$ at $37^{\circ} \mathrm{C}$ and $\alpha=180^{\circ}$; comparison of XENETIX ${ }^{\circledR 350 / V i s i p a q u e ~}{ }^{\circledR 320}$ (A) and comparison of XENETIX ${ }^{\circledR 350 / V i s i p a q u e ~}{ }^{\circledR} 270$ (B).

Note: Statistical significance is represented by ${ }^{* *}$ for $0.001<P<0.0$ I.

Abbreviation: ns, not significant. 
and Visipaque ${ }^{\circledR} 320$ while flushing Visipaque ${ }^{\circledR} 270$ was found to be slightly different from flushing XENETIX ${ }^{\circledR} 350$.

\section{Discussion}

Taking into account the marked effects of both hydrodynamics and temperature on the efficiency of power port flushing after $\mathrm{CM}$ injection, the extreme results (Figure 2A and B) are reported in Figure 8. It is noticeable that the effectiveness of rinsing at $37^{\circ} \mathrm{C}$ and $\alpha=180^{\circ}$ is found to be highly significant with respect to rinsing at $23^{\circ} \mathrm{C}$ and using a power port needle bevel orientation $\alpha=0^{\circ}$.

The first point to be noted is that according to previous results ${ }^{19}$ it is always preferable to direct the bevel of the Huber port needle towards the opposite of the outlet $\left(\alpha=180^{\circ}\right.$; Figure 1). This orientation leads to a better distribution of the shear rate of fluid injected into the port chamber thus permitting a better flushing.

The second point to be noted is that temperature plays a determinant role in the efficiency of the flushing. It appears highly preferable to use flushing fluids at $37^{\circ} \mathrm{C}$ (Figure 8) rather than at $23^{\circ} \mathrm{C}$. The reasons for such behavior are likely related to the thermo-rheological properties of the CM. As a matter of fact, from a rheological point of view, $\mathrm{CM}$ are Newtonian fluids (the viscosity is independent of the flow level) and present high values of viscosity. The dependence of viscosity with respect to the temperature is indeed classical; these measurements are reported in Figure 9A and B. The values of viscosity given by the manufacturers are reported on the figures and are in accordance with the measured values in the present study. The temperature dependence of the viscosity regarding two classical fluids currently used in human pathology, namely saline solution and lipid suspension $(200 \mathrm{mg} / \mathrm{mL})$, is reported in the Figure 9 A and B for

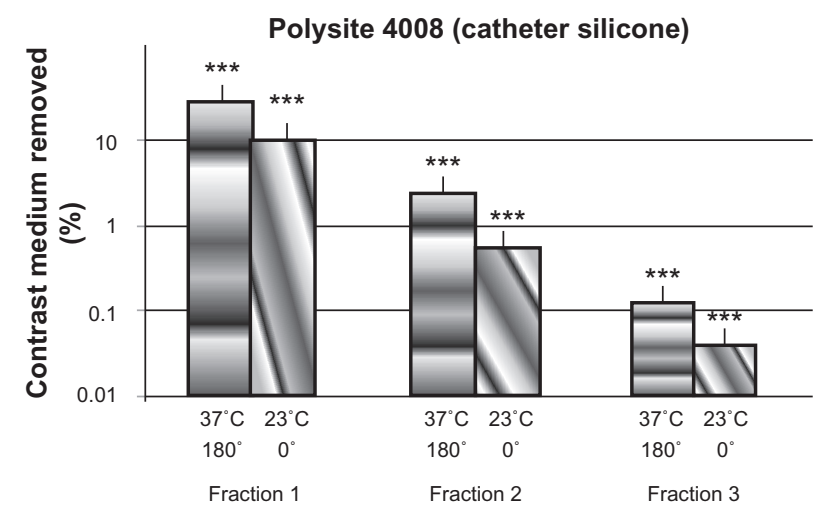

Figure 8 Semi logarithmic representation of the comparison of the percentage of removed XENETIX ${ }^{\circledR 350}$ after three successive flushing fractions of $10 \mathrm{~mL}$, for two temperatures of flushing $\left(37^{\circ} \mathrm{C}\right.$ and $\left.23^{\circ} \mathrm{C}\right)$ and two needle bevel orientations. Note: Statistical significance is represented by $* * *$ for $P<0.001$.
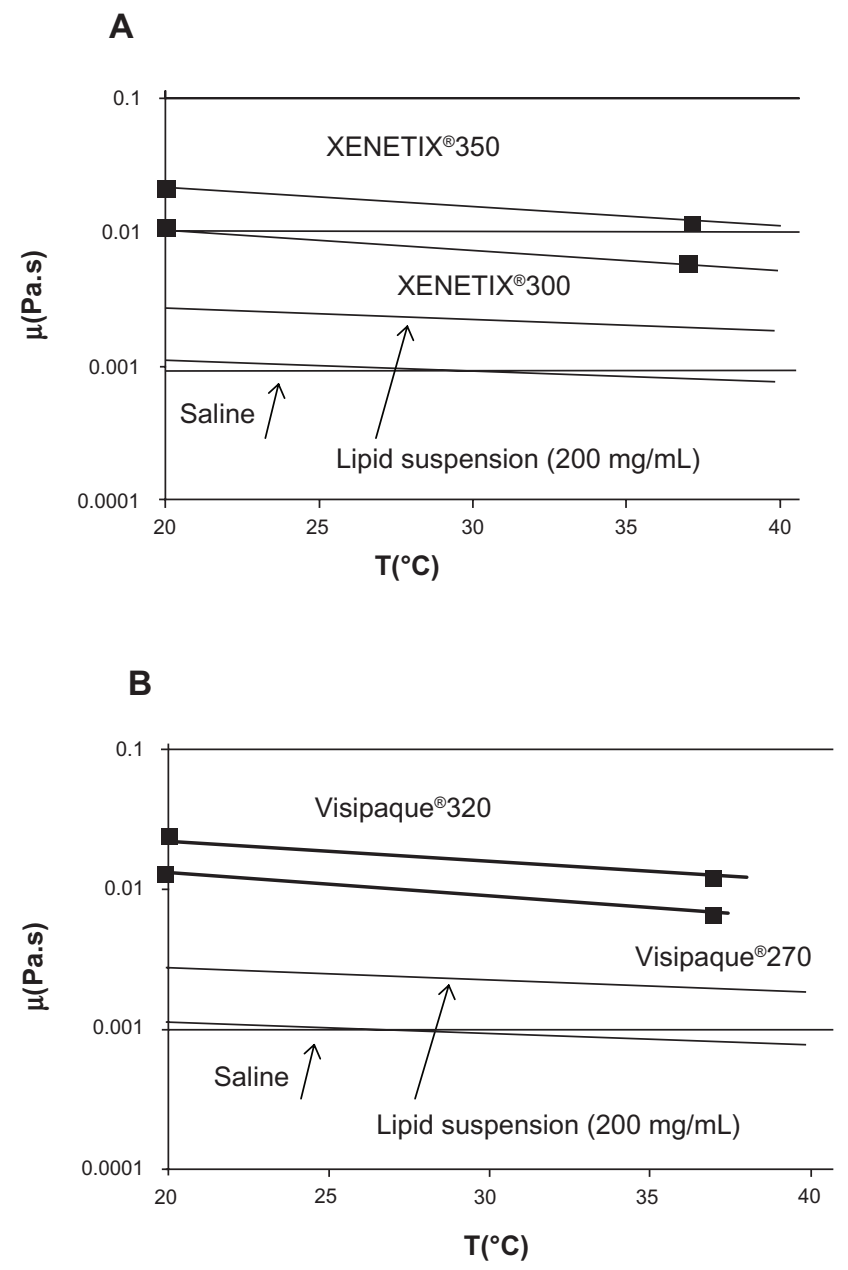

Figure 9 Semi logarithmic representation of the measured temperature dependence of the dynamic viscosity of the $\operatorname{XENETIX~}^{\circledR}(\mathbf{A})$ and Visipaque ${ }^{\circledR}(\mathbf{B})$ and comparison with saline and a lipid suspension for injection.

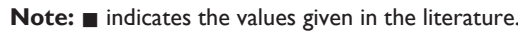

Abbreviation: $\mathrm{T}$, temperature.

comparison. It is clear that heating the $\mathrm{CM}$ is an absolute necessity to reduce its viscosity thus permitting easier injection. However, even when heating the flushing liquid, viscosity variations between the flushing liquid and the $\mathrm{CM}$ still remain important. Consequently, the subsequent shear stress produced against the $\mathrm{CM}$ interface remains insufficient to ensure effective rinsing as shown in the experimental results, even under better temperature and hydrodynamic conditions, port flushing efficiency remains definitively low (Figure 8).

Indeed, the rheological properties of the $\mathrm{CM}$ are clearly responsible for the difficulty in implementing effective flushing of the power port. The understanding of the impact of temperature on the flushing process can be clarified by examining the thermal exchange process that exists in the port chamber. The thermal conductivities of the $\mathrm{CM}$ at $37^{\circ} \mathrm{C}$ have been measured and the results obtained are reported in the Table 2. 
Table 2 Measured values of the thermal conductivity of the contrast medium retained in this study (XENETIX ${ }^{\circledR}$ and Visipaque ${ }^{\circledR}$ )

\begin{tabular}{ll}
\hline & $\begin{array}{l}\text { Thermal conductivity } \\
\text { (W/m/K) }\end{array}$ \\
\hline XENETIX $^{\circledR 350}\left(37^{\circ} \mathrm{C}\right)$ & $0.90 \pm 0.01$ \\
XENETIX $^{\circledR 300}\left(37^{\circ} \mathrm{C}\right)$ & $0.80 \pm 0.01$ \\
Visipaque $^{\circledR} 270\left(37^{\circ} \mathrm{C}\right)$ & $0.75 \pm 0.02$ \\
Visipaque $^{\circledR 320}\left(37^{\circ} \mathrm{C}\right)$ & $0.84 \pm 0.02$ \\
Saline $\left(23^{\circ} \mathrm{C}\right)$ & $0.60 \pm 0.02$ \\
\hline
\end{tabular}

Note: The value of the thermal conductivity of saline is reported for comparison.

Moreover, the CM thermal conductivity is found to be directly dependent on the iodine concentration, as shown in Figure 10. In both Table 2 and Figure 10, the values of the thermal conductivity of the saline solution at ambient temperature have been reported for comparison. The important point to be noted is that in all cases the CM conductivity was found to be higher than the saline solution conductivity. Next, the behavior of the interface that exists at $37^{\circ} \mathrm{C}$ between the $\mathrm{CM}$ and the saline solution intended to be injected initially at ambient temperature is described in Figure 11. This clearly shows the temperature distribution in the vicinity of the interface 2 seconds after rinsing. The temperature profiles are obtained by means of a numerical simulation using $\mathrm{COMSOL}^{\circledR}$. Figure 11 shows that the main effect of the "cold" $\left(23^{\circ} \mathrm{C}\right)$ rinsing fluid is to generate a superficial colder layer of $\mathrm{CM}$ with a thickness magnitude of $1 \mathrm{~mm}$. As CM viscosity is temperature dependent (Figure 9A and B), this superficial layer will be of higher viscosity, and thus a supplementary major handicap to improve flushing. All rheological and thermal data concerning the $\mathrm{CM}$ and saline solution are summarized in Figure 12. It is then easy to visualize the significant differences on both

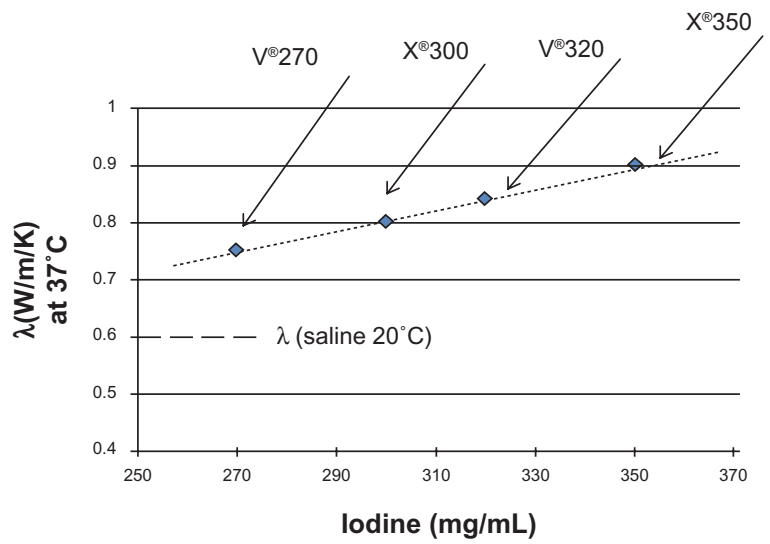

Figure 10 Measured thermal conductivity of the contrast medium as a function of the iodine concentration. The thermal conductivity of the saline at $20^{\circ} \mathrm{C}$ is given for comparison.

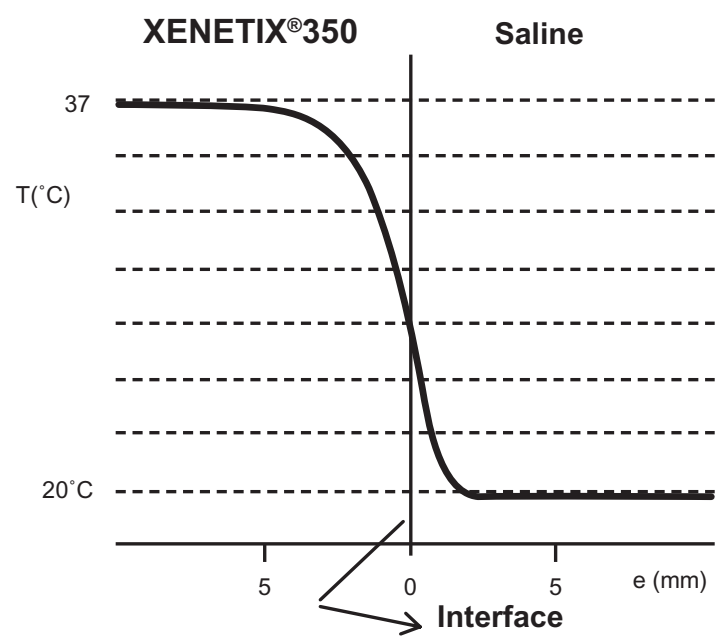

Figure II Calculated profile of temperature at the interface of XENETIX ${ }^{\circledR 350}$ at $37^{\circ} \mathrm{C}$ and injected saline at $20^{\circ} \mathrm{C}$.

Abbreviation: $\mathrm{T}$, temperature.

the rheological and thermal parameters of the CM and the flushing liquid.

Two types of TIVADs are classically reported in the literature: the central chest ports that are inserted on the patient's chest, and the upper periphery ports inserted in the arm or forearm. ${ }^{24,25}$ Nowadays, it is tempting to use them in daily radiology practice. Some radiologist teams have already started to perform the "power contrast enhanced computerized tomography (CT)" examinations, namely in patients presenting with cardiovascular and oncology conditions, by using "power port" CM injections. ${ }^{17,21,22}$ Preventing patient pain or discomfort related to the superficial venipuncture (to inject CM before CT examination) is indeed essential. The development of "high pressure" device components that are resistant to viscous CM high flow rates and thermostated to reduce the viscosity and

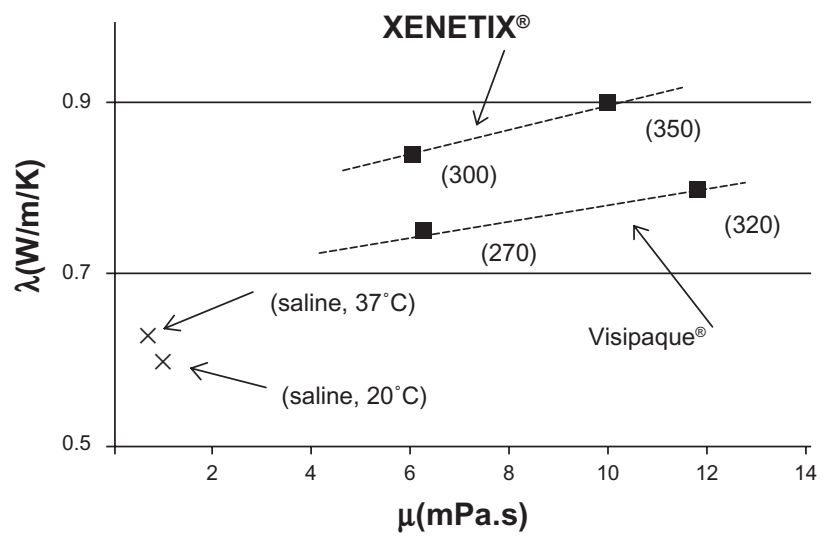

Figure 12 Dependence of the thermal conductivity of contrast medium as a function of the dynamic viscosity. The corresponding values for the saline are reported for comparison. 
facilitate the flow, thus allows "safe power CM injection" during a patient's CT examination. The referring radiologist performs the Huber port needle puncture of the power port septum, under strict aseptic conditions, and securely fastens the needle through the port overlying skin. Though a little time-consuming, this innovative technique seems promising and prevents risks of CM extravasation. ${ }^{21-23}$ However, the present study shows significant CM retention in the chamber, less into the connected catheter (Figure 3), and no significant difference in the catheter component (silicone or polyurethane) used. Thus, the results of the present study suggest that the persistence of endoluminal CM is, undoubtedly, a "potential seat of pollution". As a matter of fact, $\mathrm{CM}$ can have a $\mathrm{pH}$ ranging from 6.8 to 7.7 according to the iodine concentration. In a physico-chemical point of view, any further power port injection of basic drugs such as antibiotics and oncology products (whose $\mathrm{pH}$ ranges from 3.5 to 6 ) would potentially involve local acid basic reactions between those drugs and the trapping CM. This might lead to the possibility of device lumen soluble salt formation in situ. In addition, even in the best flushing conditions tested (see Figure 8 and Table 1), the persistence of endoluminal power device $\mathrm{CM}$, might contribute to long-term delivery of trisubstituted benzene nuclei, whose potential toxic impact is unknown in human patients.

As in vivo means to identify venous port device CM trapping are very limited, quantification implementation was performed in vitro. A significant proportion of CM (around $70 \%$ ) was found to be retained in the port chamber, and less in the catheter lumen (due to its lower intraluminal surface), with no difference according to device material type (silicone versus polyurethane). The present study suggests that heating the flushing saline solution fraction increases the efficiency of the device flushing. However, even by flushing a larger quantity of saline solution $(100 \mathrm{~mL})$, device flushing quality still looks very ineffective. Considering the routine use of CM injection throughout the so called "power port" device and the potential use of power port CM injection in daily radiology practice worldwide, we claim that power ports are not properly flushed out even under the best conditions tested. The persistence of CM in the device lumen as high as $70 \%$ to $90 \%$ may cause a "potential seat of pollution", leading to the production device lumen salt precipitate and long-term delivery of trisubstituted benzene nuclei into the patient's circulation. Moreover, any further supplementary $\mathrm{CM}$ injection will increase CM trapping and thus increase the risk of subsequent partial occlusion and malfunction of the device.

\section{Conclusion}

The work presented here is part of the global questioning ${ }^{17}$ posed by the injection of CM throughout TIVADs. Clearly, poor CM flushing is related to both the physico-chemical and rheological properties of the CM and is thus unavoidable. The secondary risk of CM catheter port obstruction is particularly relevant regarding high osmolarity and high-viscosity of CM. The present in vitro experimental data do not argue in favor of this type of use with central venous catheter ports. This concept is applicable to any type of catheter including Peripheral inserted central catheter (PICC) lines, as well. We advocate for using a supplementary intravenous line to be removed after extemporaneous CT examination, except in selected patients presenting with limited venous access and seemingly no superficial vein. Following a recent study, ${ }^{11}$ our findings suggest that CM injection into TIVADs should be used with circumspection in exceptional cases. In such cases, the flushing solution $(0.9 \% \mathrm{NaCl})$ should be injected after heating to $37^{\circ} \mathrm{C}$, via an implanted Huber needle whose bevel is oriented opposite the power port catheter exit. This might contribute to limit CM trapping and thus decrease the subsequent risk of clogging and mechanical malfunction of the TIVAD.

\section{Acknowledgments}

The authors thank Perouse Medical for providing the TIVADs necessary for the study. The authors thank Guerbet France for providing XENETIX ${ }^{\circledR} 350$. The authors thank FRESENIUS KABI France for providing SMOF lipids.

\section{Disclosure}

The authors report no conflicts of interest in this work.

\section{References}

1. Adler A, Yaniv I, Steinberg R, et al. Infectious complications of implantable ports and Hickman catheters in paediatric haematologyoncology patients. $J$ Hosp Infect. 2006;62(3):358-365.

2. Ahmadi J, Izadyar M, Ashjaei B, et al. Study of advantages and disadvantages of totally implanted venous access device. Acta Med Iranica. 2006;44(3):199-202.

3. Hall P, Cedermark B, Swedenborg J. Implantable catheter system for longterm intravenous chemotherapy. J Surg Oncol. 1989;41(1): 39-41.

4. Herrmann KA, Waggershauser T, Sittek H, Reiser MF. Liver intraarterial chemotherapy: use of the femoral artery for percutaneous implantation of catheter-port systems. Radiology. 2000;215(1):294-299.

5. Hirota $\mathrm{T}$, Yamagami $\mathrm{T}$, Tanaka $\mathrm{O}$, et al. Brain infarction after percutaneous implantation of port-catheter system via the left subclavian artery. $\mathrm{Br} J$ Radiol. 2002;75(898):799-804.

6. Yamagami T, Kato T, Iida S, Hirota T, Nishimura T. Management of end hole in placement of port-catheter system for continuous hepatic arterial infusion chemotherapy using the fixed catheter tip method. AJR Am J Roentgenol. 2005;184(4):1332-1339. 
7. Yamagami T, Terayama K, Yoshimatsu R, Matsumoto T, Miura H, Nishimura T. Use of N-butyl cyanoacrylate in implantation of a port-catheter system for hepatic arterial infusion chemotherapy with the fixed-catheter-tip method: is it necessary? AJR Am J Roentgenol. 2008;191(5):1523-1529.

8. Berger P. La bonne gestion des chambres implantables. [The good management of implantable ports]. ANAES, lettre circulaire DH/EM1. October 28, 1996:96-6225. French.

9. Matillon Y. Evaluation de la qualité de l'utilisation et de la surveillance des chambres à cathéters implantables. [Quality assessment of the use and monitoring of implantable ports]. ANAES. January 16, 2001:1-57.

10. Baskin JL, Pui CH, Reiss U, et al. Management of occlusion and thrombosis associated with long-term indwelling central venous catheters. Lancet. 2009;374(9684):159-169. French.

11. Pittiruti M, Hamilton H, Biffi R, MacFie J, Pertkiewicz M; ESPEN. ESPEN Guidelines on Parenteral Nutrition: central venous catheters (access, care, diagnosis and therapy of complications). Clin Nutr. 2009;28(4):365-377.

12. Ragni MV, Journeycake JM, Brambilla DJ. Tissue plasminogen activator to prevent central venous access device infections: a systematic review of central venous access catheter thrombosis, infection and thromboprophylaxis. Haemophilia. 2008;14(1):30-38.

13. Rigsby CK, Gasber E, Seshadri R, Sullivan C, Wyers M, Ben-Ami T. Safety and efficacy of pressure-limited power injection of iodinated contrast medium through central lines in children. AJR Am J Roentgenol. 2007;188(3):726-732.

14. Vescia S, Baumgärtner AK, Jacobs VR, et al. Management of venous port systems in oncology: a review of current evidence. Ann Oncol. 2008;19(1):9-15.

15. Biffi R, Orsi F, Pozzi S, et al. Best choice of central venous insertion site for the prevention of catheter-related complications in adult patients who need cancer therapy: a randomized trial. Ann Oncol. 2009;20(5): 935-940.
16. Goltz JP, Machann W, Noack C, Hahn D, Kickuth R. Feasibility of power contrast injections and bolus triggering during $\mathrm{CT}$ scans in oncologic patients with totally implantable venous access ports of the forearm. Acta Radiol. 2011;52(1):41-47.

17. Bonciarelli G, Batacchi S, Biffi R, et al; Gruppo Aperto di Studio Accessi Venosi Centrali a Lungo Termine (Study Group on Long-Term Central Venous Access). GAVeCeLT* consensus statement on the correct use of totally implantable venous access devices for diagnostic radiology procedures. J Vasc Access. 2011;12(4):292-305.

18. Guiffant G, Durussel JJ, Merckx J, Flaud P, Vigier JP, Mousset P. Flushing of intravascular access devices (IVADs) - efficacy of pulsed and continuous infusions. J Vasc Access. 2012;13(1):75-78.

19. Guiffant G, Durussel JJ, Flaud P, Vigier JP, Merckx J. Flushing ports of totally implantable venous access devices, and impact of the Huber point needle bevel orientation: experimental tests and numerical computation. Med Devices (Auckl). 2012;5:31-37.

20. Al-Ajlan SA. Measurement of thermal properties of insulation materials by using transient plane source technique. Applied Thermal Engineering. 2006;26(17-18):2184-2191.

21. Schummer C, SakrY, Steenbeck J, Gugel M, Reinhart K, Schummer W. Risk of extravasation after power injection of contrast media via the proximal port of multilumen central venous catheters: case report and review of the literature. Rofo. 2010;182(1):14-19.

22. Marcy PY, Thariat J, Figl A. Power injection via a venous port: a new challenge for radiologists. Rofo. 2010;182(6):536-537.

23. O'Sullivan P, Brown M, Hartnett B, Mayo JR. Central line pump infusion and large volume mediastinal contrast extravasation in CT. Br J Radiol. 2006;79(944):e75-e77.

24. Marcy PY, Magné N, Castadot P, et al. Is radiologic placement of an arm port mandatory in oncology patients?: analysis of a large bi-institutional experience. Cancer. 2007;110(10):2331-2338.

25. Marcy PY. Central venous access: techniques and indications in oncology. Eur Radiol. 2008;18(10):2333-2344.
Medical Devices: Evidence and Research

\section{Publish your work in this journal}

Medical Devices: Evidence and Research is an international, peerreviewed, open access journal that focuses on the evidence, technology, research, and expert opinion supporting the use and application of medical devices in the diagnosis, treatment and management of clinical conditions and physiological processes. The identification of novel

\section{Dovepress}

devices and optimal use of existing devices which will lead to improved clinical outcomes and more effective patient management and safety is a key feature. The manuscript management system is completely online and includes a quick and fair peer-review system. Visit http://www. dovepress.com/testimonials.php to read real quotes from authors. 